\title{
Effect of Arsenic Exposure on Human Telomerase Reverse Transcriptase (hTERT) Gene Expression: Risk of Cardiovascular Disease
}

\author{
Khaleda L ${ }^{1}$, Al-Forkan $\mathrm{M}^{1 *}$, Wali FB ${ }^{2}$, Alam MJ ${ }^{1}$, Datta ${ }^{1}$, Shawon $\mathrm{II}^{1}$, Hosain ${ }^{3}$, Rahman $\mathrm{MZ}^{4}$ \\ ${ }^{1}$ Department of Genetic Engineering and Biotechnology, Faculty of Biological Sciences, University of \\ Chittagong, Chittagong, Bangladesh; ${ }^{2}$ Department of Biochemistry and Biotechnology, Faculty of \\ Basic Medical and Pharmaceutical Sciences, University of Science and Technology Chittagong, \\ Chittagong, Bangladesh; ${ }^{3}$ Department of Cardiac Surgery, Chittagong Medical College Hospital, \\ Chittagong, Bangladesh; ${ }^{4}$ Department of Pathology, Chittagong Medical College, Chittagong, \\ Bangladesh
}

\begin{abstract}
Background: Exposure to inorganic arsenic (iAs) through drinking water is currently a serious threat to public health of millions of people worldwide including Bangladesh. Some recent studies have shown that telomere dysfunction is emerging as an important factor in the pathogenesis of different cardiovascular diseases. Arsenic plays significant role on telomere dysfunction by altering the expression of telomere-related genes.

Objective: The study was aimed to investigate the effects of arsenic on hTERT mRNA levels and their combined role in increasing CVD susceptibility.

Methods: In this cross sectional study, total of 50 CVD patients who underwent open heart surgery were recruited. Urine, nail and cardiac tissue samples were collected and analysed for As. Blood samples were quantified for $h T E R T$ expression analysis using real-time polymerase chain reaction.

Results: The hTERT mRNA expression was found approximately 10 fold higher in the As-exposed patients than the As-unexposed patients $(p<0.01)$. A strong positive correlation $(p<0.01, \mathrm{r}>0.3)$ was found between the hTERT mRNA levels and As contents in the cardiac tissue, nail and urine samples of the study subjects. The significant increase (approx. 4 fold) in the hTERT mRNA expression was found in the patients with coronary artery disease (CAD) than the non-CAD patients.

Conclusions: The results of the study suggest that arsenic exposure increases hTERT mRNA expression which may in turn modify As-induced cardiovascular outcomes. The findings of this study will help to look deep into the association of As exposure in cardiovascular disease pathogenesis to open a new window in the diagnosis and treatment procedure of CVD.
\end{abstract}

Keywords: Arsenic, hTERT, Cardiovascular disease, Telomerase

\section{Introduction}

Arsenic (As) is a well-known poison and widely distributed element in the environment with which humans usually come into contact through food, water, air, and soil. ${ }^{1,2}$ Chronic arsenic exposure is associated with increased risk for arsenic skin

*Correspondence: Mohammad Al-Forkan, Department of Genetic Engineering and Biotechnology, Faculty of Biological Sciences, University of Chittagong, Chittagong, Bangladesh; e-mail: alforkangeb@gmail.com lesions, cancer, cardiovascular diseases and other adverse health outcomes. ${ }^{3,4}$ One potential mechanism of arsenic toxicity is telomere dysfunction. ${ }^{4}$ Telomeres are made up of a repetitive sequence (TTAGGG) of six nitrogenous bases rich in guanine. This sequence is repeated over several thousand base pairs at the 3' end of DNA (4 to 15 kilobases in humans). ${ }^{5}$ When cells divide and DNA replicates, some nucleotide content is lost from each 
telomere. ${ }^{6}$ This loss of genetic material corresponds to the phenomenon called "the end replication problem'. ${ }^{7}$ If this shortening of telomeres is not repaired, they eventually reach a critical length that triggers cell senescence or apoptosis. Because telomere length (TL) shortens with age in most human tissues, it is considered a potential biomarker of aging and a potential contributor to age-related diseases. ${ }^{8}$

Telomere maintenance is tightly regulated by telomerase and other telomere-associated proteins. Telomerase is capable of preventing the loss of chromosomes at each cell division by adding telomeric sequences (TTAGGG repeats) to the ends of chromosomes. Human telomerase consists of an RNA subunit [human telomerase RNA (hTR)] and the protein components, including an enzymatic subunit (telomerase reverse transcriptase or hTERT) and dyskerin. ${ }^{9}$ Typically, telomerase activity is reduced or even absent in most adult somatic cells, the exception being cells with a strong potential for division, like active lymphocytes and certain types of stem cells. ${ }^{10}$

The mechanism for the effect of arsenic on the telomere length may probably mediate through upregulation of telomerase (TERT). There is some support that arsenic alters the telomeres: arsenic increased telomere attrition, chromosomal rearrangements, and apoptotic cell death in mouse embryos with short telomeres. Some in vitro studies have shown that arsenic increases the activity of TERT. Also, in people exposed to arsenic via drinking water $(1-1000 \mu \mathrm{g} / \mathrm{L})$ in Inner Mongolia, TERT expression was positively associated with both arsenic concentrations in water and in nails and the severity of hyperkeratosis, a common arsenicrelated skin lesion. ${ }^{10,11}$

Recent epidemiological studies have supported the role of telomere length and telomerase activity in cardiovascular disease pathogenesis. $., 7,12,13$

Cardiovascular disease (CVD) in general and coronary artery disease (CAD) in particular is a leading cause of mortality and morbidity worldwide. ${ }^{7,10,14}$ Current in vitro evidence shows that human vascular smooth muscle cells (VSMCs) under normoxia and hypoxia continue proliferating through telomerase activation and elevated human telomerase reverse transcriptase (hTERT) expression, suggesting a potential role of telomerase in vascular remodeling. The up-regulation of telomerase and its catalytic hTERT protein during stages of atherosclerotic evolution may implicate a role of telomerase in vascular remodeling underlying Atherogenesis. ${ }^{12}$ Increased expressions of TERT and telomerase activity has recently been reported in atherosclerotic plaques. ${ }^{13}$ However, the role of TERT dysregulation during atherosclerosis formation remains unknown. Some studies have also reported shorter telomeres in subjects with e.g. chronic heart failure, atherosclerosis, ventricular dysfunction, coronary artery calcification and aortic valve stenosis. $^{7,15}$

The aim of this study was to investigate the effect of arsenic exposure on hTERT mRNA expression in increasing As-induced CVD susceptibility. In this study, the hTERT mRNA expression level was compared in between As-exposed and unexposed CVD patients' groups to investigate the role of telomerase expression in increasing CVD susceptibility in arsenic exposed patients.

\section{Material and Methods}

Study subjects and sample collection: In this cross sectional study, a total of $50 \mathrm{CVD}$ patients were recruited who underwent open heart surgery in the Department of Cardiac Surgery, Chittagong Medical College and Hospital and National Heart Foundation Hospital \& Research Institute, Dhaka. Pre-operative nail, urine samples and a very small portion of postoperative cardiac tissue which usually peeled off and disposed after the surgery were collected from each of the study subject. Peripheral blood samples were collected from the subjects for RNA extraction. Questionnaires were administered to all participants to obtain demographic and clinical information. Ethical clearance was taken from the Ethical Review Committee of Chittagong Medical College and Hospital, Chittagong. Each subject was informed about the study and written consent was obtained. 
Arsenic exposure measurements: Urine, nail and cardiac tissue samples were analyzed for As contents by Hydride Generation Atomic Absorption Spectrophotometry (HG-AAS) at the International Centre for Diarrhoeal Disease Research, Bangladesh (icddr,b) Dhaka using Shimadzu AA-7000 Atomic Absorption Spectrophotometer (Japan). Background-corrected absorbance values were recorded, and the peak heights were used for quantization using the "WizAAard" software (Shimadzu).

RNA extraction from blood samples: Peripheral blood mononuclear cell (PBMC) was used for RNA extraction in this study. Three $\mathrm{mL}$ of peripheral venous blood was collected in lavender-top tube containing EDTA as an anticoagulant. PBMCs were isolated after centrifugation at 1000xg for 10 minutes. One $\mathrm{mL}$ of TRIzol ${ }^{\mathrm{TM}}$ Reagent was added to the separated PBMCs and total RNA was extracted following TRIzol Reagent user guideline. ${ }^{16}$ Extracted RNA was then quantified using A Nano Drop Spectrophotometer 2000 (Thermo Scientific, USA). RNase inhibitor was added to the extracted RNA and stored at $-80^{\circ} \mathrm{C}$.

Quantitative real-time polymerase chain reaction (PCR) for analyzing hTERT expression. The first strand cDNA synthesis was conducted in a total reaction volume of $30 \mu 1$ using GoScript ${ }^{\mathrm{TM}}$ Reverse Transcription System (Promega, USA). The cDNA sample was amplified by the GoTaq ${ }^{\circledR}$ qPCR Master Mix Systems (Promega, USA) using the following primers: hTERT-2164S (5'-GCC TGA GCT GTA CTT TGT CAA-3'and hTERT-2620A (5'-CGC AAA CAG CTT GTT CTC CAT GTC-3'). The cycling conditions were $95^{\circ} \mathrm{C}$ for $300 \mathrm{~s}$, followed by 45 cycles of $95^{\circ} \mathrm{C}$ for $30 \mathrm{~s}, 58^{\circ} \mathrm{C}$ for $10 \mathrm{~s}$, and $72^{\circ} \mathrm{C}$ for 40s. The hTERT mRNA levels were normalized to $\beta$-actin mRNA levels, which were determined in the same tube as the target gene (hTERT). No template control was used as negative control. Relative change in hTERT gene expression was analyzed by $2^{-\Delta \Delta C_{T}}$ method from qRT-PCR experiments using the expression of $\beta$-actin gene as reference. ${ }^{17}$ The sample used as control was denoted as calibrator sample (CVD patients from As- unaffected areas) and finally, the samples tested (CVD patients from As affected areas) were denoted as test sample. The ratio of the target gene expression was calculated in the test sample over the calibrator sample. This ratio is the expression fold change or relative quantification of gene expression. All the reactions were done in triplicates and average $\mathrm{Ct}$ (cycle threshold) values was taken to analyze the results.

Statistical analysis: For data analysis, to reduce the skewness evident in hTERT, the data was transformed by taking the $\log$ (base ${ }_{10}$ ). Simple linear regression model and Spearmen correlation coefficients were used to evaluate the association between continuous dependent variables (hTERT expression) and independent predictor variables. Continuous variables were expressed as "Mean \pm Standard Errors of Mean (SEM)" and categorical variables as percentages. Demographic and clinical characteristics were compared using Chi-square test or Fisher's exact test, Student's $t$-test and ANOVA. Statistical analysis was performed using Microsoft Excel and SPSS (v.24). All reported $p$ values are two-sided and values less than 0.05 were considered statistically significant.

\section{Results}

Of the 50 study subjects, 36 patients were from known As-affected areas and 14 patients were from known As-unaffected areas. No significant differences were observed between the patients from As-affected areas and the patients from Asunaffected areas with regard to age, gender, BMI and smoking (table I).

Table I: Demographic characteristics of study population $(\mathrm{n}=50)$

\begin{tabular}{lccc}
\hline \multicolumn{1}{c}{ Variables } & $\begin{array}{c}\text { Patients from As- } \\
\text { affected areas }(\boldsymbol{n}=\mathbf{3 6})\end{array}$ & $\begin{array}{c}\text { Patients from As- } \\
\text { unaffected areas } \\
(\boldsymbol{n}=\mathbf{1 4})\end{array}$ & p value \\
\hline $\begin{array}{l}\text { Age }(\text { years }) \\
\text { Sex }\end{array}$ & $48.97 \pm 1.71$ & $49.64 \pm 1.44$ & $0.766^{*}$ \\
Male $(\%)$ & $28(77.78 \%)$ & $9(64.29 \%)$ & $0.474^{* *}$ \\
$\begin{array}{l}\text { Female }(\%) \\
\text { Habit of Smoking }\end{array}$ & $8(22.22 \%)$ & $5(35.71 \%)$ & \\
Smoker $(\%)$ & $24(66.67 \%)$ & $8(57.14 \%)$ & $0.533^{* *}$ \\
$\begin{array}{l}\text { Non-Smoker }(\%) \\
\text { BMI (x } \pm \text { SE), }\end{array}$ & $12(33.33 \%)$ & $6(42.86 \%)$ & \\
Kg/m & $24.35 \pm 1.02$ & $23.23 \pm 2.56$ & $0.491^{*}$ \\
\hline * Age and BMI were shown as mean \pm SE and analyzed by Student's
\end{tabular}


$t$-test. ** Sex and habit of smoking were shown as percent and analyzed by Fisher-exact test. Significance level, $p<0.05$

Clinical characteristics including cases of coronary artery disease (CAD), hypertension and as concentrations in nail, urine and cardiac tissues were found significantly higher in the patients from Asaffected areas than the patients from As-unaffected areas (table II).

Table II: Clinical characteristics of study population $(\mathrm{n}=50)$

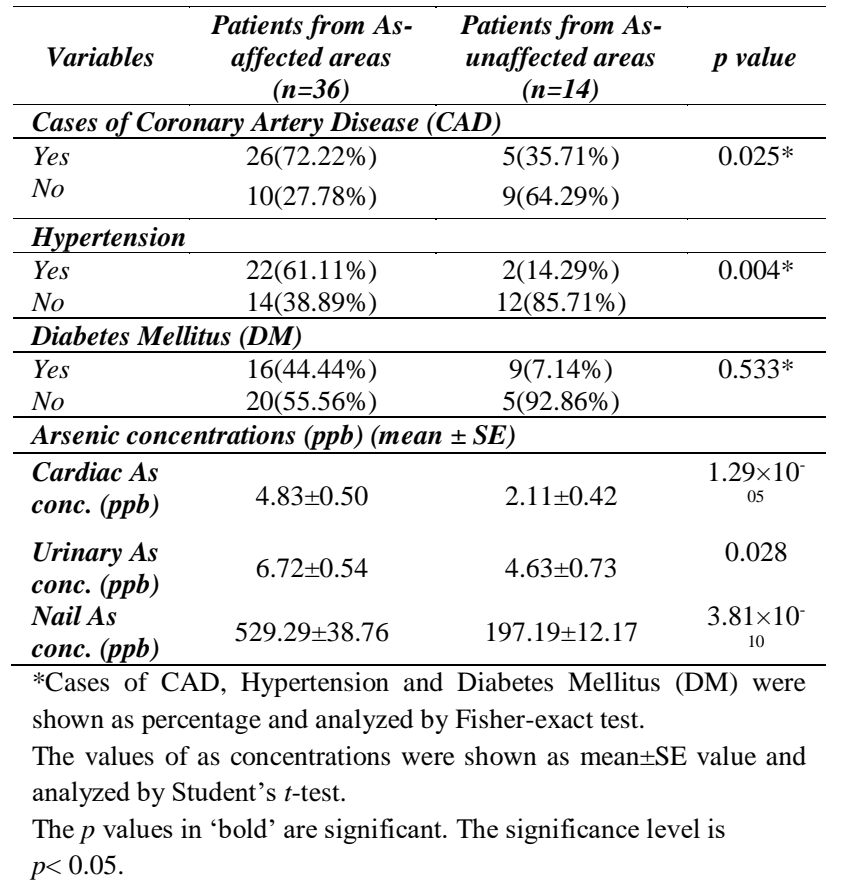

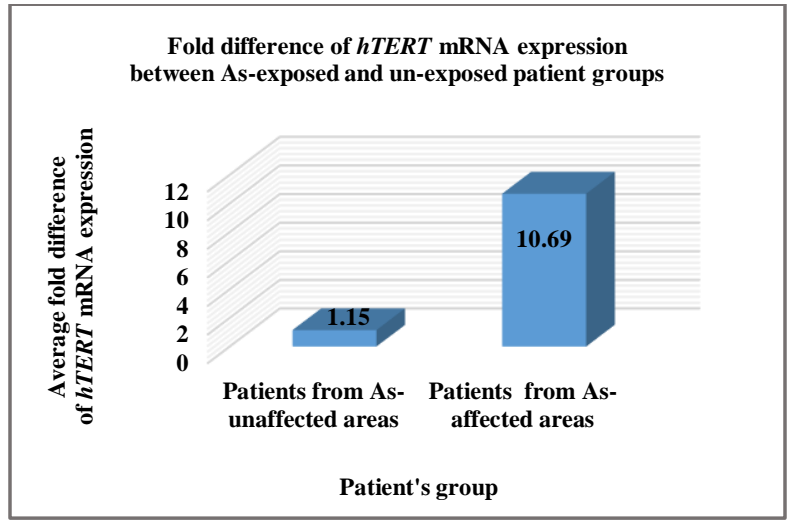

Figure 1: The average fold changes of $h T E R T$ gene expression in the patients from As-affected areas in comparison with the patients from As-unaffected areas. The patients from As-affected areas showed approx. 10 fold higher $h T E R T$ mRNA expression than the patients from As-unaffected areas. The hTERT mRNA levels of both Asexposed and un-exposed patients' groups were normalized to $\beta$-actin mRNA levels.
hTERT expression and Age: Higher hTERT mRNA levels were found higher in the older patients with higher age (figure 2). But no significant difference ( $p=0.762$ ) was found for the association of age with hTERT mRNA expression. Patients under the study were categorized into three age groups younger adult ( $<35$ year), middle aged adult $(\geq 35-49)$ and older adult ( $\geq 50$ year). Among these three age groups, the mean levels of $h T E R T$ were lowest in the $<35$ year age group (32.17), followed by the $\geq 35-49$ year age group (31.53) and then the $\geq 50$ year age group (31.39) (figure 3).

Relative expression analysis of hTERT gene in patient groups: Relative expression of hTERT gene in As-affected patients group compared to the Asunaffected patients group had been calculated as fold changes by $\Delta \Delta \mathrm{C}_{\mathrm{T}}$ method. The patients from Asaffected areas showed approximately 10 fold higher (normalized with reference gene, $\beta$-actin) expression of $h T E R T$ gene respectively than the patients from As-unaffected areas (figure 1).

As exposure and hTERT expression: All the blood samples showed detectable levels of hTERT mRNA by real-time PCR. The increase in the relative hTERT mRNA expression level among study subjects was significantly associated with the concentrations of cardiac As, urine As and nail As (figure 4). In Figure 4(A) Spearman coefficient, r= 0.625 and $p=1 \times 10^{-6}$ represented the significant association of $h T E R T$ expression with cardiac As concentration. Similar significant association was also found for the mRNA levels of $h T E R T$ with the concentration of urinary As $(\mathrm{r}=0.447, p=0.001)$ and nail As $\left(\mathrm{r}=0.734, p=1.3 \times 10^{-9}\right)$ shown in figure $4(\mathrm{~B})$ and $(\mathrm{C})$ respectively.

Relative hTERT mRNA expression levels and coronary atherosclerosis disease (CAD): Among our study subjects, significantly $(p=0.025)$ more CAD patients originated from As-affected areas than from As-unaffected areas (table I). Among the Asexposed patients group, we found 86\% (31/36) patients (figure $5 \mathrm{~A}$ ), and among the As-unexposed patients group, we found $36 \%$ (5/14) patients with coronary artery disease (CAD) (figure 5B). 


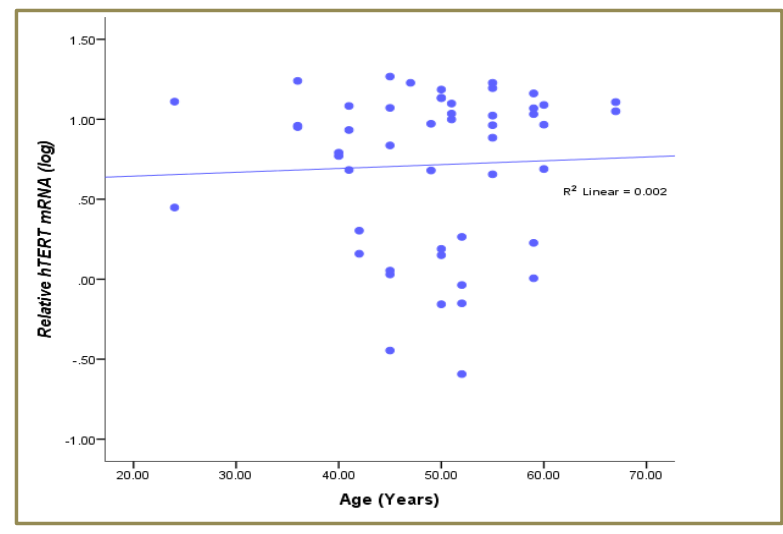

Figure 2: Association of relative $h T E R T$ mRNA expression levels with Age. Here, hTERT expression level is shown as log transformed value. The trend line indicated the association of higher hTERT mRNA levels with the higher Age (Simple Linear regression model: $\mathrm{n}=50, p=0.762)$. Spearman correlation coefficient, $\mathrm{r}=0.078$ indicates very weak correlation with $h T E R T$ mRNA levels with Age. Significance level for correlation was 0.05 .

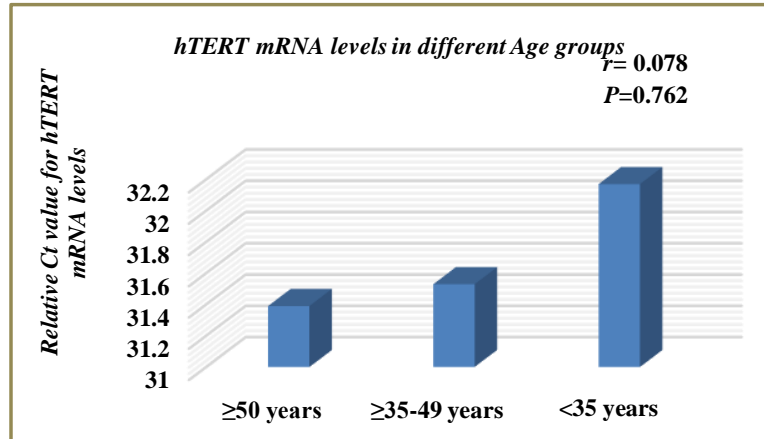

Age group (years)

Figure 3: Association of relative $\mathrm{C}_{\mathrm{T}}$ value for $h T E R T$ mRNA levels and different Age groups. Here, $h T E R T$ expression level is shown as $\mathrm{C}_{\mathrm{T}}$ value. Higher $\mathrm{C}_{\mathrm{T}}$ value indicates the lower $h T E R T$ expression. Patients with higher Age showed the higher hTERT mRNA expression levels (lower $\mathrm{C}_{\mathrm{T}}$ value).

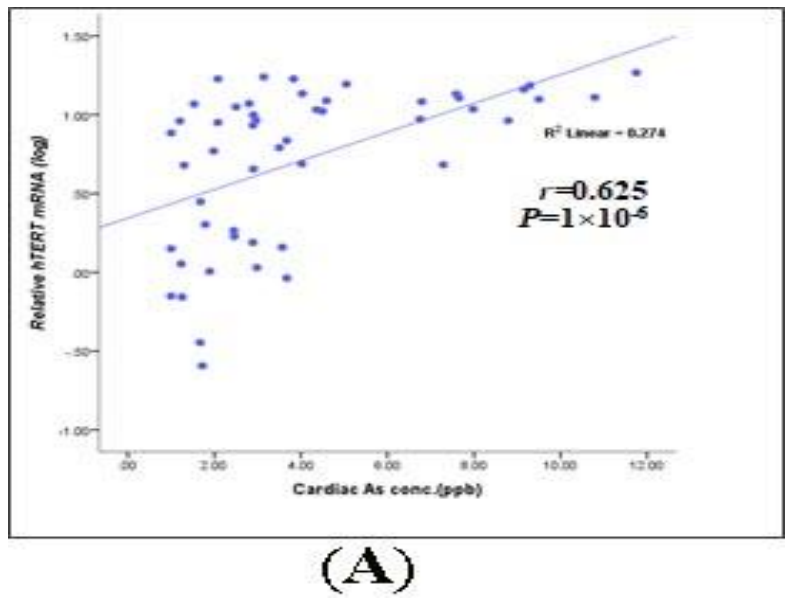

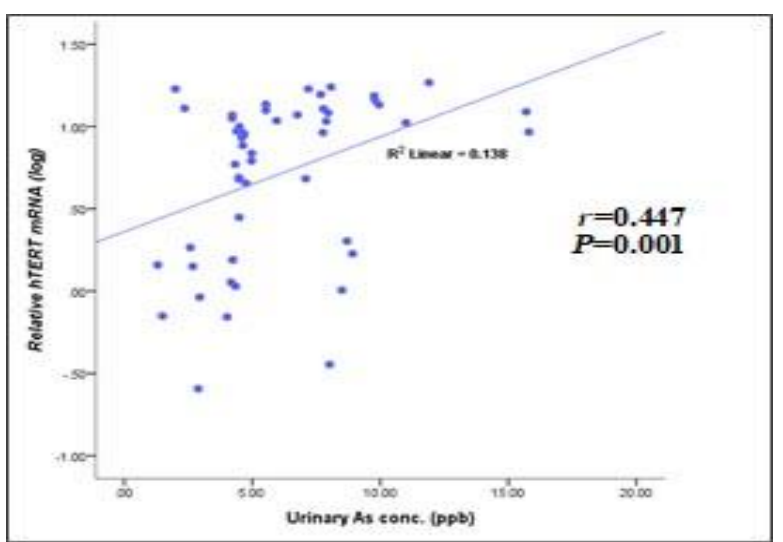

(B)

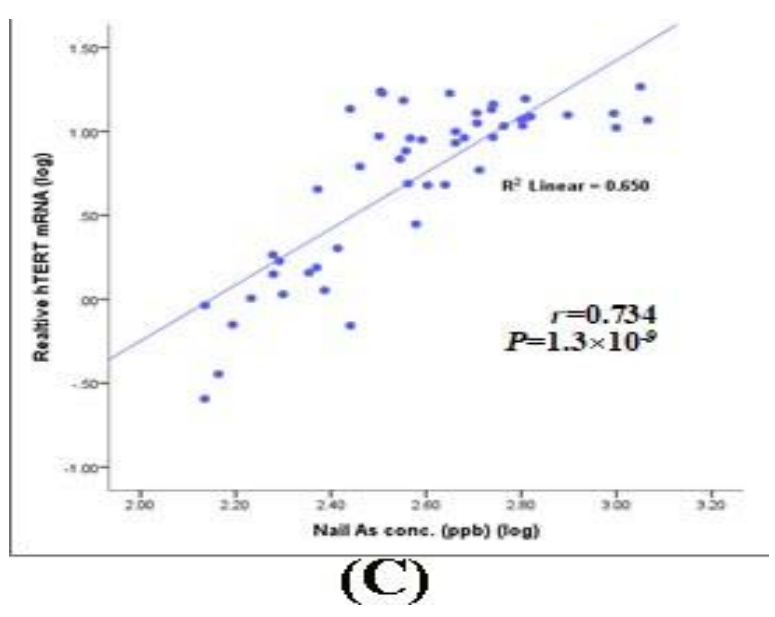

Figure 4: Association between $h T E R T$ mRNA expression levels and Cardiac As conc. (A), Urinary As conc. (B), Nail As conc. (C). For each of the three graphs the trend line indicates the significant association of higher $h T E R T$ mRNA levels (log) with the higher As concentrations in cardiac tissue, urine and nail samples (Simple linear regression model: $\mathrm{n}=50, P<0.01)$. In each graph Spearman correlation coefficient indicated positive correlation (0-1).

*The strength of Spearman Correlation Coefficient ranges as- 0.400.59 "moderate" and 0.60- 0.79 "strong". Significance level for correlation was 0.01 .

Relative expression of $h T E R T$ gene in CAD patients group compared to the non-CAD patients group had been calculated as fold changes by $\Delta \Delta \mathrm{C}_{\mathrm{T}}$ method. The CAD patients showed approximately 4 fold higher (normalized with reference gene, $\beta$-actin) expression of hTERT gene than the non-CAD patients group (figure 6). 

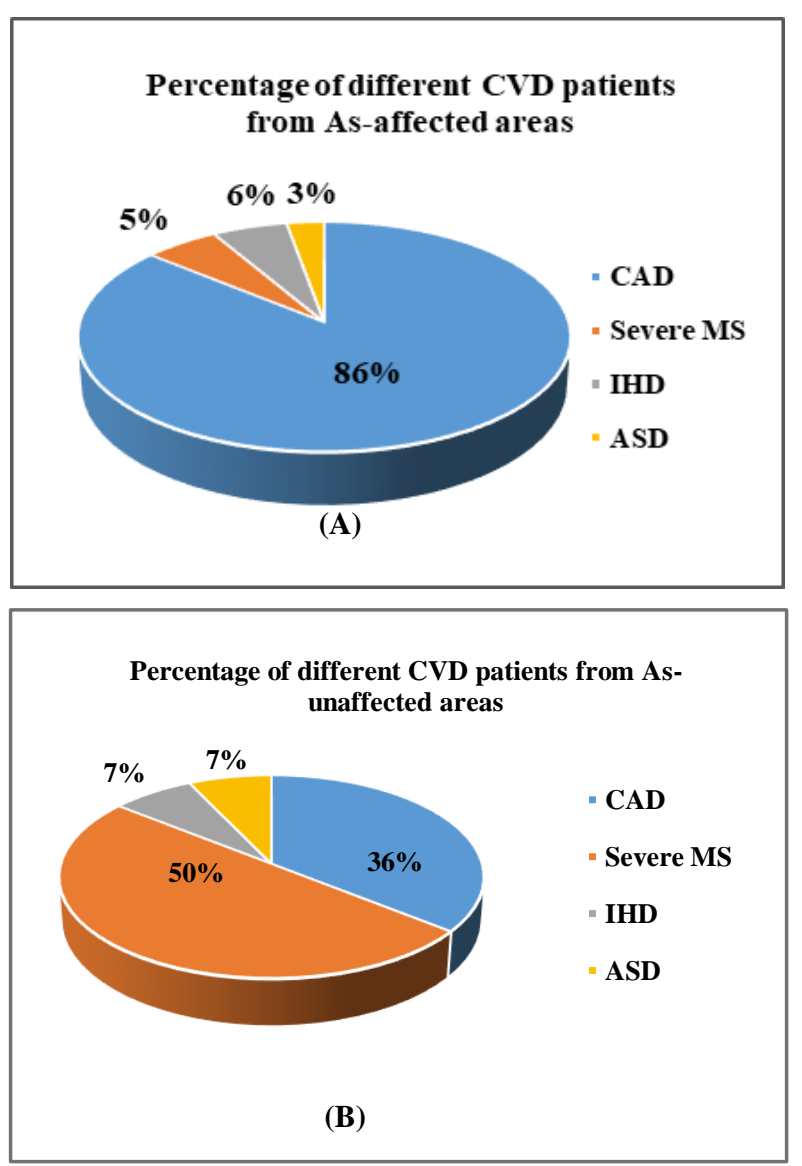

Figure 5: Distribution of different types of CVD occurrence in (A) patients from As-affected areas and (B) patients from As-unaffected areas. The cases of coronary artery disease (CAD) was noticeably higher among the As-exposed patients group in comparison to As-unexposed patients group.

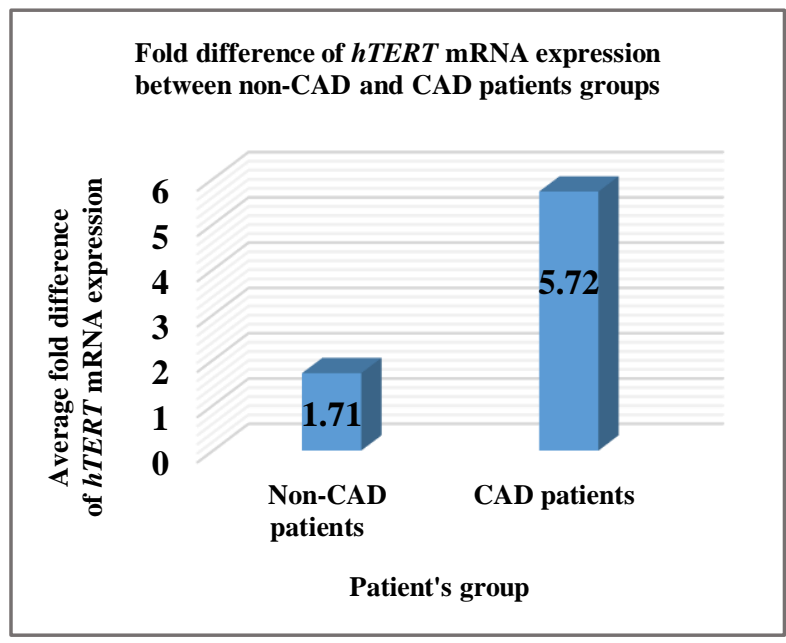

Figure 6: The average fold changes of hTERT gene expression in the CAD patients in comparison with non-CAD patients. The patients diagnosed with coronary artery disease (CAD) showed approx. 5 fold higher $h T E R T$ mRNA expression than the non-CAD patients. The $h T E R T$ mRNA levels of both As-exposed and un-exposed patients' groups were normalized to $\beta$-actin mRNA levels.

\section{Discussion}

The study reported an association between arsenic exposure and elevated level of hTERT mRNA expression and their role on cardiovascular disease pathogenesis. In vitro studies of human cord blood cells and human cell lines have shown that arsenic exposure can both increase and decrease telomere length and telomerase activity. ${ }^{14,15}$ Whereas a few published studies of the association between arsenic exposure and telomere length (TL) tend to be small, recent epidemiologic studies linked arsenic exposure to longer TL in peripheral blood and saliva and altered peripheral blood expression of genes involved in telomere maintenance. ${ }^{10,18-22}$ This study examined the effects of as exposure on hTERT mRNA levels in blood cells from CVD patients exposed to a varied range of As. In this study, Asexposed patients group showed approx. 10-fold higher expression of hTERT mRNA than Asunexposed patients group. A strong correlation (positive) was found between $h T E R T$ mRNA levels and as concentrations in urine, nail and cardiac tissue samples $(p<0.01, r>0.3)$. hTERT expression in blood cells was highly associated with the concentrations of as in cardiac tissue. Cardiovascular tissue, specifically the auricle is a good biomarker of the risk of cardiovascular health due exposure to arsenic. ${ }^{28}$ Urinary arsenic is usually considered as the most reliable indicator of recent exposure to arsenic and Toenail As concentration has been reported to reflect chronic exposure of As up to 6-12 months. ${ }^{10,27}$ In the present study, hTERT expression was also associated with the concentrations of As in urine and nails. The findings of this study suggest that arsenic exposure is associated with elevated hTERT mRNA expression in blood cells which is collaborative with the findings of other authors. ${ }^{10,19}$ However, the molecular mechanisms of increasing $h T E R T$ gene expression by as are still unclear.

The association of telomere with atherosclerosis and CVD has been supported by a large number of studies. ${ }^{5,11,12}$ Decreased hTERT mRNA expression and shorter telomere was found associated with atherosclerosis in various studies. ${ }^{7,24-26}$ In this study, among 50 study subjects, 31 patients were diagnosed 
with coronary artery diseases and the patients with CAD showed 4 fold higher hTERT mRNA expression than non-CAD patients. Some recent studies have reported that the expression of TERT and telomerase activity is increased in atherosclerotic plaques. In human atherosclerosis telomerase is activated and TERT expression correlates with the extent of the disease; however, the mechanisms underlying telomerase activation and the physiological role of inducible TERT expression in atherosclerosis remain to be discovered. ${ }^{11,12}$ In correlation with these findings, this study suggests the association of increased hTERT expression with the increased risk of coronary artery diseases.

This study indicated a significant association between $h T E R T$ expression and arsenic exposure. A positive correlation between $h T E R T$ expression and coronary artery diseases has also been reported. It was also found significant difference $(p<0.05)$ in the occurrence rate of $\mathrm{CAD}$ in between As-exposed patients' groups and unexposed patients' groups. There are separate studies on the effect of Arsenic exposure on hTERT expression and CVD risk. So far, this work is the first one to investigate the interaction of arsenic exposure with hTERT mRNA expression and their combined role in increasing CVD susceptibility. The results of this study imply that arsenic exposure increases telomerase expression which in turns modifies As-induced cardiovascular outcomes.

\section{Conclusion}

Arsenic exposure has been detected as one of the risk factors for developing cardiovascular diseases. This is the first study showing that hTERT mRNA expression in blood cells is positively associated with As exposure in humans and their combined effects increase the risk of cardiovascular diseases. Chronic arsenic exposure increases the hTERT gene expression. Moreover, higher hTERT mRNA expression was observed in patients diagnosed with coronary artery disease (CAD). This finding represents the association of telomerase activity with CVD and suggests telomerase may play role in the pathophysiology related to developing atherosclerosis. Thus, As intoxication increases the susceptibility of cardiovascular diseases by upregulating $h T E R T$ gene expression.

\section{Acknowledgement}

This research was supported by the fund of Research and Publication Cells, University of Chittagong. The authors also thankful to the patients who actively supported with their enthusiastic cooperation to carry out the study.

\section{References}

1. Vahidnia A, Van der Voet GB, De Wolff FA. Arsenic neurotoxicity-a review. Human \& experimental toxicology. 2007; 26:823-32.

2. Hughes MF, Beck BD, Chen Y, Lewis AS, Thomas DJ. Arsenic exposure and toxicology: a historical perspective. Toxicological Sciences. 2011; 123:305-32.

3. Minatel BC, Sage AP, Anderson C, Hubaux R, Marshall EA, Lam WL, Martinez VD. Environmental arsenic exposure: from genetic susceptibility to pathogenesis. Environment international. 2018; 112:183-97.

4. Zhang C, Kibriya MG, Jasmine F, Roy S, Gao J, Sabarinathan M, Shinkle J, Delgado D, Ahmed A, Islam T, Eunus M. A study of telomere length, arsenic exposure, and arsenic toxicity in a Bangladeshi cohort. Environmental research. 2018; 164:346-55.

5. Salpea KD, Humphries SE. Telomere length in atherosclerosis and diabetes. Atherosclerosis. 2010; 209:35-8

6. Dean SG, Zhang C, Gao J, Roy S, Shinkle J, Sabarinathan M, Argos M, Tong L, Ahmed A, Islam MT, Islam T. The association between telomere length and mortality in Bangladesh. Aging (Albany NY). 2017; 9:1537.

7. Saliques S, Zeller M, Lorin J, Lorgis L, Teyssier JR, Cottin Y, Rochette L, Vergely C. Telomere length and cardiovascular disease. Archives of cardiovascular diseases. 2010; 103:454-9.

8. Sanders JL, Newman AB. Telomere length in epidemiology: a biomarker of aging, age-related disease, both, or neither?. Epidemiologic reviews. 2013; 35:11231.

9. Cohen SB, Graham ME, Lovrecz GO, Bache N, Robinson PJ, Reddel RR. Protein composition of 
catalytically active human telomerase from immortal cells. Science. 2007; 315:1850-3.

10. Mo J, Xia Y, Ning Z, Wade TJ, Mumford JL. Elevated human telomerase reverse transcriptase gene expression in blood cells associated with chronic arsenic exposure in Inner Mongolia, China. Environmental health perspectives. 2008; 117:354-60.

11. Gao J, Roy S, Tong L, Argos M, Jasmine F, Rahaman R, Rakibuz-Zaman M, Parvez F, Ahmed A, Hore SK, Sarwar G. Arsenic exposure, telomere length, and expression of telomere-related genes among Bangladeshi individuals. Environmental research. 2015; 136:462-9.

12. Liu SC, Wang SS, Wu MZ, Wu DC, Yu FJ, Chen WJ, Chiang FT, Yu MF. Activation of telomerase and expression of human telomerase reverse transcriptase in coronary atherosclerosis. Cardiovascular Pathology. $2005 ; 14: 232-40$

13. Qing $H$. Telomerase reverse transcriptase in therosclerosis. Ph.D Thesis. University of Kentucky. 2017.

14. Bhattacharyya J, Mihara K, Bhattacharjee D, Mukherjee $\mathrm{M}$. Telomere length as a potential biomarker of coronary artery disease. The Indian journal of medical research. 2017; 145:730.

15. Samani NJ, Boultby R, Butler R, Thompson JR, Goodall AH. Telomere shortening in atherosclerosis. The Lancet. 2001; 358:472-3.

16. TRIzol Reagent User Guide - Pub. no. MAN0001271 Rev. A [Internet] ThermoFisher Scientific; 2016.

17. Livak KJ, Schmittgen TD. Analysis of relative gene expression data using real-time quantitative PCR and the 2- $\Delta \Delta$ CT method. methods. 2001; 25:402-8.

18. Ferrario D, Collotta A, Carfi M, Bowe G, Vahter M, Hartung T, Gribaldo L. Arsenic induces telomerase expression and maintains telomere length in human cord blood cells. Toxicology. 2009; 260:132-41.

19. Zhang TC, Schmitt MT, Mumford JL. Effects of arsenic on telomerase and telomeres in relation to cell proliferation and apoptosis in human keratinocytes and leukemia cells in vitro. Carcinogenesis. 2003;24:1811-7.
20. Chatterjee D, Bhattacharjee P, Sau TJ, Das JK, Sarma N, Bandyopadhyay AK, Roy SS, Giri AK. Arsenic exposure through drinking water leads to senescence and alteration of telomere length in humans: A case-control study in West Bengal, India. Molecular carcinogenesis. 2015; 54:800-9.

21. Fillman T, Shimizu-Furusawa $\mathrm{H}, \mathrm{Ng} \mathrm{CF}$, Parajuli RP, Watanabe C. Association of cadmium and arsenic exposure with salivary telomere length in adolescents in Terai, Nepal. Environmental research. 2016; 149:8-14.

22. Li H, Engström K, Vahter M, Broberg K. Arsenic exposure through drinking water is associated with longer telomeres in peripheral blood. Chemical research in toxicology. 2012; 25:2333-9.

23. Ameer $\mathrm{SS}, \mathrm{Xu} \mathrm{Y}$, Engström $\mathrm{K}$, Li $\mathrm{H}$, Tallving $\mathrm{P}$, Nermell B, Boemo A, Parada LA, Peñaloza LG, Concha G, Harari F. Exposure to inorganic arsenic is associated with increased mitochondrial DNA copy number and longer telomere length in peripheral blood. Frontiers in cell and developmental biology. 2016; 4:87.

24. De Meyer T, Nawrot T, Bekaert S, De Buyzere ML, Rietzschel ER, Andrés V. Telomere length as cardiovascular aging biomarker: JACC review topic of the week. Journal of the American College of Cardiology. 2018; 72:805-13.

25. Matthews C, Gorenne I, Scott S, Figg N, Kirkpatrick P, Ritchie A, Goddard M, Bennett M. Vascular smooth muscle cells undergo telomere-based senescence in human atherosclerosis: effects of telomerase and oxidative stress. Circulation research. 2006; 99:156-64.

26. Carulli, L., 2014. Telomeres and atherosclerosis. NMCD. Nutrition Metabolism and Cardiovascular Diseases, pp.1-7.

27. Chakraborti D, Rahman MM, Mukherjee A, Alauddin M, Hassan M, Dutta RN, Pati S, Mukherjee SC, Roy S, Quamruzzman Q, Rahman M. Groundwater arsenic contamination in Bangladesh-21 Years of research. Journal of Trace Elements in Medicine and Biology. 2015; 31:237-48.

28. Veas IP, Silva DR, Barrios CS, Arsenic status of cardiovascular tissues from cardiac patients. Journal of Cardiology and Current Research. 2018; 11:78-88. 